\title{
Coantagonism of glutamate receptors and nicotinic acetylcholinergic receptors disrupts fear conditioning and latent inhibition of fear conditioning
}

\author{
Thomas J. Gould ${ }^{1}$ and Michael C. Lewis \\ Temple University, Psychology Department/Neuroscience Program, Philadelphia, Pennsylvania 19122, USA
}

\begin{abstract}
The present study investigated the hypothesis that both nicotinic acetylcholinergic receptors (nAChRs) and glutamate receptors ( $\alpha$-amino-3-hydroxy-5-methyl-4-isoxazole propionate receptors (AMPARs) and $\mathrm{N}$-methyl-Daspartate glutamate receptors (NMDARs)) are involved in fear conditioning, and may modulate similar processes. The effects of the nAChR antagonist mecamylamine administered alone, the AMPAR antagonist NBQX administered alone, and the NMDAR antagonist MK-801 administered alone on cued fear conditioning, contextual fear conditioning, and latent inhibition of cued fear conditioning were examined. In addition, the effects of coadministration of either mecamylamine and NBQX or mecamylamine and MK-801 on these behaviors were examined. Consistent with previous studies, neither mecamylamine nor NBQX administered alone disrupted any of the tasks. However, coadministration of mecamylamine and NBQX disrupted both contextual fear conditioning and latent inhibition of cued fear conditioning. In addition, coadministration of mecamylamine with a dose of MK-801 subthreshold for disrupting either task disrupted both contextual fear conditioning and latent inhibition of cued fear conditioning. Coadministration of mecamylamine and NBQX, and coadministration of mecamylamine with a dose of MK-801 subthreshold for disrupting fear conditioning had little effect on cued fear conditioning. These results suggest that nAChRs and glutamate receptors may support similar processes mediating acquisition of contextual fear conditioning and latent inhibition of fear conditioning.
\end{abstract}

A large body of research has been directed at understanding the neural, cellular, and molecular processes that underlie fear conditioning and tasks that modulate conditioning, such as latent inhibition. This focus provides a means to not only understand the neurobiology of learning, but also to understand disease states that can be modeled with these tasks. Fear conditioning measures amygdala- and hippocampus-dependent learning (contextual fear conditioning), as well as amygdala-dependent and hippocampus-independent learning (cued fear conditioning) within the same subject (Kim and Fanselow 1992; Phillips and LeDoux 1992, 1994; Rudy 1993; Logue et al. 1997). Latent inhibition is a robust and long-lasting phenomenon, in which repeated exposure to a conditioned stimulus (CS) without consequence retards subsequent conditioning to that stimulus when paired with an unconditioned stimulus (US) (Lubow 1989; Weiner 2003; Lewis and Gould 2004). Latent inhibition, which is thought to index the ability to ignore irrelevant information, has been implicated as a model of the attention deficits associated with schizophrenia (Braff 1993; Gray 1998; Lubow et al. 2000; Kilts 2001; Escobar et. al 2002; Vaitl et al. 2002). Similar to contextual fear conditioning, latent inhibition involves the hippocampus (Kaye and Pearce 1987; Schmajuk et al. 1994, 2000; Han et al. 1995; Oswald et al. 2002; Pouzet et al. 2004). The present study investigated whether glutamate receptors (i.e., $\mathrm{N}$-methylD-aspartate glutamate receptors [NMDARs] and $\alpha$-amino-3hydroxy-5-methyl-4-isoxazole propionate receptors [AMPARs]) and nicotinic acetylcholinergic receptors [nAChRs] interact during fear conditioning and latent inhibition of cued fear conditioning.

Nicotine enhances contextual fear conditioning, but not cued fear conditioning (Gould and Wehner 1999b; Gould 2003;

\footnotetext{
'Corresonding author.

E-mail tgould@temple.edu; fax (215) 204-5539.

Article and publication are at http://www.learnmem.org/cgi/doi/10.1101/ Im.89105.
}

Gould and Higgins 2003; Gould and Lommock 2003). In addition, nicotine enhances latent inhibition of cued fear conditioning (Rochford et al. 1996; Gould et al. 2001). The cellular and molecular mechanisms through which nicotine facilitates contextual fear conditioning and latent inhibition of cued fear conditioning are unknown, but multiple possibilities exist; ligandmediated events at nAChRs can activate fast synaptic currents (Roerig et al. 1997; Hefft et al. 1999), can stimulate the release of glutamate, dopamine, norepinephrine, and GABA (Grady et al. 1992; Alkondon et al. 1996, 1997; Sershen et al. 1997), can increase calcium influx (Eilers et al. 1997; Wonnacott 1997; Sorenson et al. 1998; Broide and Leslie 1999; Porter et al. 1999; Nomikos et al. 2000; Berg and Conroy 2002; Dajas-Bailador et al. 2002a; Perry et al. 2002), and can activate signaling cascades involving ERK/MAPK, CaMKII/IV, and CREB (Chang and Berg 2001; Nakayama et al. 2001; Berg and Conroy 2002; DajasBailador et al. 2002b; Utsugisawa et al. 2002; Brunzell et al. 2003). In addition, nicotine can enhance long-term potentiation (LTP) and reverse deficits in LTP associated with aging or administration of GABAergic agonists (Fujii et al. 1999, 2000; Fujii and Sumikawa 2001; Yamazaki et al. 2002), and administration of nicotine alone can induce LTP (He et al. 2000; Matsuyama et al. 2000). Thus, nicotine could facilitate contextual fear conditioning and latent inhibition of cued fear conditioning through mechanisms similar to those involved in LTP.

Despite research demonstrating that nicotine administration enhances contextual fear conditioning and latent inhibition of cued fear conditioning, data indicating that nAChR antagonist mecamylamine is without effects on the tasks (Gould and Wehner 1999b; Gould et al. 2001) and data indicating that nAChR subtype null mice perform the tasks normally (Paylor et al. 1998; Caldarone et al. 2000) make the role of nAChRs in acquisition of fear conditioning and latent inhibition unclear. The null effect of $\mathrm{nAChR}$ inhibition suggests either that nAChR activation is not critically involved, but enhances acquisition of these tasks, or 
that nAChRs are involved in acquisition of these tasks, but a parallel process also supports acquisition of these tasks and can compensate for nAChR inhibition. One possible neurotransmitter system that could regulate analogous processes is the glutamate system.

Contextual fear conditioning and latent inhibition of cued fear conditioning have been shown to be dependent on NMDAR activation (Fanselow and Kim 1994; Fanselow et al. 1994; Gould et al. 2002; Lewis and Gould 2004; Davis and Gould 2005). The NMDAR is unique from other receptors in the central nervous system, in that it is both ligand and voltage gated (Nowak et al. 1984). Binding of glutamate to the NMDAR is not sufficient to cause depolarization. Concurrent membrane depolarization in conjunction with glutamate binding is required to remove the magnesium block and allow rapid influx of calcium through NMDA ion channels (Nowak et al. 1984). This feature of the NMDAR may make it well suited for supporting synaptic plasticity and learning (Riedel et al. 2003). Indeed, NMDAR function is necessary for some forms of LTP (for review, see Lisman 2003).

Glutamate binding at AMPA/kainate receptors offers an efficient process for mediating the concurrent membrane depolarization necessary for NMDAR-associated currents (Herron et al. 1986). Many in vitro studies of LTP have found that AMPARs are inserted into the postsynaptic membrane following LTP (for review, see Sheng and Kim 2002; Bredt and Nicoll 2003). However, in humans, the maximally tolerated dose of the AMPA/kainate antagonist LY293538 did not disrupt cognitive function (Sang et al. 1998). In addition, behavioral studies and LTP studies that have used antagonists with greater selectivity for AMPARs than kainate receptors have not consistently found learning-related memory impairments or deficits in LTP (Parada et al. 1992; for review of AMPARs and learning, see Danysz et al. 1995; Misztal and Danysz 1995; Sato et al. 1995; Stephens and Cole 1996; Li et al. 1997; Lu and Wehner 1997; Filliat et al. 1998; Mead and Stephens 1999; Kapus et al. 2000; Lees 2000; Aultman and Moghaddam 2001; Pitsikas et al. 2002; Willmore et al. 2002; Gutierrez et al. 2004). For example, Lu and Wehner (1997) found that in C57BL/ 6 mice, cued and contextual fear conditioning was insensitive to the AMPAR antagonist NBQX at a dose three times higher than a dose of NBQX that produced 100\% protection against audiogenic seizures in mice (Swedberg et al. 1995). The differences in purported AMPAR involvement in in vitro and in vivo models of learning and synaptic plasticity may relate to differences in AMPAR involvement in acquisition versus consolidation. It is also possible that AMPARs may be involved with acquisition of in vivo tasks, but a parallel process may compensate for AMPAR inhibition.

Evidence suggests that nAChRs and AMPARs may play a similar role in mediating NMDAR-associated currents. Aramakis and Metherate (1998) report that, developmentally, a synergistic relationship exists between nAChRs and NMDARs in auditory cortex; nicotine enhanced late excitatory postsynaptic potentials (EPSP) in the presence of an AMPA/kainate antagonist, but failed to enhance late EPSPs in the presence of a NMDAR antagonist. In addition, previous in-vitro work has shown that hippocampal currents are present in pyramidal cells after antagonism of NMDARs and AMPARs, and these residual currents are inhibited by nAChR antagonism (Hefft et al. 1999). Further, Roerig et al. (1997) demonstrated in the developing visual cortex that the $\alpha 4 \beta 2$ nAChR antagonist dihydro- $\beta$-erythroidine (DH $\beta E$ ) abolished residual currents present after application of the NMDA antagonist APV and the AMPA/kainate antagonist CNQX. Whereas nAChRs are involved in many presynaptic events (McGehee et al. 1995; Role and Berg 1996), these electrophysiological results suggest $\mathrm{nAChRs}$ may function postsynaptically to regulate cellular currents. In support of a postsynaptic location of nAChRs, Roerig et al. (1997) used photo stimulation to directly activate AChRs during whole-cell patch recording in the presence and absence of DH $\beta E$ to demonstrate that the inward currents were mediated by postsynaptic nAChRs. In addition, other studies also report that nAChRs mediate postsynaptic events (Alkondon et al. 1996; Zhang et al. 1996; Frazier et al. 1998a,b; Chu et al. 2000; Ji et al. 2001; Alkondon and Albuquerque 2002) and that nAChRs are located on hippocampal dendritic spines (Fabian-Fine et al. 2001).

The inward postsynaptic currents mediated by nAChRs could contribute to NMDA-mediated synaptic plasticity. In a 2001 study, Ji et al. demonstrated that currents mediated by postsynaptic hippocampal pyramidal cell nAChRs could contribute to the depolarization necessary to remove the magnesium block of NMDARs. Further, evidence suggests that nAChRs not only occur postsynaptically, but also colocalize with AMPARs. Levy and Aoki (2002) report that in adult cortex, 73\% of AMPARpositive neurons were also nAChR positive in the postsynaptic densities. Based on these data, the authors proposed that the nAChRs could activate glutamatergic synapses and may interact with AMPARs to regulate EPSPs. These findings, taken together, suggest that nAChRs could mediate synaptic excitability in the absence of AMPAR activation.

The data reviewed thus far suggest that the lack of effect on learning observed previously with the administration of either $\mathrm{nAChR}$ antagonists or AMPAR antagonists alone is due to the ability of either nAChRs or AMPARs to mediate the concurrent membrane depolarization necessary for NMDAR activation. It is also possible that nAChRs interact with NMDARs or mediate similar processes as NMDARs. Support for this contention comes from studies that show that nAChRs mediate calcium influx and activate cell-signaling cascades similar to those activated by NMDARs (Chang and Berg 2001; Nakayama et al. 2001; Berg and Conroy 2002; Dajas-Bailador et al. 2002b; Utsugisawa et al. 2002; Brunzell et al. 2003). Thus, activation of nAChRs could both contribute to the cell depolarization necessary for activation of NMDARs and could also activate cell-signaling cascades involved in learning that are also activated by NMDARs.

The aims of the current study were to (1) examine whether coantagonism of nAChRs and AMPARs would induce deficits in behavioral tasks that have previously been shown to be insensitive to antagonism when $\mathrm{nAChR}$ or AMPAR antagonists were administered alone, and (2) examine whether nAChR and NMDAR coantagonism produces greater deficits in contextual fear conditioning and latent inhibition of cued fear conditioning than when administered separately. It was hypothesized that neither NBQX nor mecamylamine would produce deficits in contextual fear conditioning or latent inhibition of cued fear conditioning based on previous results (Lu and Wehner 1997; Gould and Wehner 1999b; Gould et al. 2001); however, coadministration of the drugs would produce deficits in these tasks. It was also hypothesized that coantagonism of nAChRs and NMDARs would produce greater deficits for these tasks than when either drug is administered alone.

\section{Results}

\section{Experiment 1: AMPA/nAChR interaction in latent inhibition}

To examine the roles of nAChRs and AMPARs in latent inhibition of cued fear conditioning, mecamylamine alone, NBQX alone, or mecamylamine and NBQX together were given prior to preexposure to the CS (i.e., latent inhibition). It was expected that mecamylamine would not block latent inhibition, based on pre- 


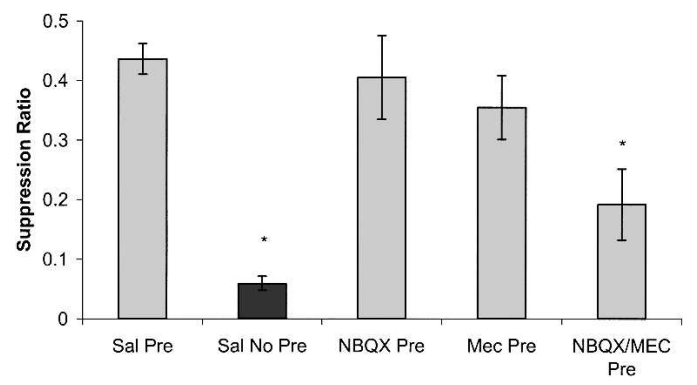

Figure 1. The effects of NBQX (30.0 mg/kg; AMPAR antagonist), mecamylamine $(1.0 \mathrm{mg} / \mathrm{kg}$; nAChR antagonist), or coadministration of the two drugs on latent inhibition of cued fear conditioning. There were significant differences between saline pre-exposed (Sal Pre) and saline non-pre-exposed (Sal No Pre) mice, indicating that latent inhibition was established. Neither NBQX (NBQX Pre) nor mecamylamine (Mec Pre) administered alone on pre-exposure day had any effect on latent inhibition. The coadministration of NBQX and mecamylamine on pre-exposure day (NBQX /Mec Pre) blocked latent inhibition of cued fear conditioning. Light gray bars represent pre-exposed groups. Dark gray bars represent non-pre-exposed groups. Error bars, \pm SEM. (*) Significantly different from saline pre-exposed mice.

vious results (Gould et al. 2001). In addition, it was expected that NBQX would not alter latent inhibition based on a preliminary study (Gould and Lewis 2003) and based on results from an experiment that examined the effects of NBQX on fear conditioning (Lu and Wehner 1997). However, if nAChRs and AMPARs are mediating similar processes involved in latent inhibition, coadministration of the two drugs should abolish latent inhibition. A one-way analysis of variance revealed an overall effect of drug $\left[F_{(4,37)}=11.04, P<0.001\right]$. Post-hoc analysis revealed significant differences between saline pre-exposed and saline non-preexposed groups $(P<0.05)$, with pre-exposed mice having higher suppression ratios compared with non-pre-exposed mice. This indicates the establishment of latent inhibition (Fig. 1). If mecamylamine has no effect on latent inhibition, we would then expect this group to have suppression ratios that are significantly higher than saline non-pre-exposed mice and similar to saline pre-exposed mice. There were significant differences between mecamylamine pre-exposed and saline non-pre-exposed groups $(P<0.05)$, but no differences were observed between the mecamylamine pre-exposed mice and the saline pre-exposed mice $(P>0.05)$, suggesting that nAChRs antagonism alone does not block the establishment of latent inhibition (Fig. 1). This result is consistent with a previous finding (Gould et al. 2001). Similarly, if NBQX has no effect on latent inhibition, we would then expect that the group-administered NBQX would have suppression ratios that are significantly higher than saline non-pre-exposed mice, but similar to saline pre-exposed mice. There were significant differences between NBQX pre-exposed and saline non-preexposed mice $(P<0.05)$, and no differences were observed between saline pre-exposed mice and NBQX treated pre-exposed mice $(P>0.05)$. This data suggests that AMPAR antagonism alone does not disrupt latent inhibition (Fig. 1).

To examine the possibility that coantagonism of nAChRs or AMPARs could disrupt latent inhibition, mecamylamine and NBQX were coadministered prior to pre-exposure. If coantagonism of these two receptors blocks latent inhibition, we would then expect the suppression ratios for this group to be significantly lower than saline pre-exposed mice and similar to saline non-pre-exposed mice. Post-hoc analysis revealed significant differences between the mecamylamine/NBQX pre-exposed and saline pre-exposed groups $(P<0.05)$ and no differences were observed between the coadministration group and saline non-preexposed group $(P>0.05)$, indicating that the coantagonism of these receptors blocked the establishment of latent inhibition (Fig. 1). The time to initiate the first lick of the testing trial was measured and compared between groups. A one-way ANOVA revealed no differences in lick latencies for any groups $\left[F_{(4,37)}=0.802, P>0.05\right]$. Thus, drug conditions and preexposure conditions did not disrupt initiation of licking on testing day.

To examine the possibility that the lack of effect observed in both the NBQX pre-exposed and mecamylamine pre-exposed groups could have resulted from lasting effects of either drug administered on pre-exposure day that carried over to training day, NBQX or mecamylamine was administered to non-preexposed mice and compared with saline non-pre-exposed mice. A one-way ANOVA revealed no differences between saline nonpre-exposed mice and either NBQX or mecamylamine non-preexposed mice $\left[F_{(2,21)}=1.297, P>0.05\right]$, suggesting that neither NBQX nor mecamylamine had lasting effects on training day (data not shown).

\section{Experiment 2: NMDA/nAChR interactions in latent inhibition}

Activation of nAChRs can depolarize neurons (Roerig et al. 1997; Hefft et al. 1999) and also activate cell-signaling cascades by mediating calcium influx (Chang and Berg 2001; Nakayama et al. 2001; Berg and Conroy 2002; Dajas-Bailador et al. 2002b; Utsugisawa et al. 2002; Brunzell et al. 2003). This ability of nAChRs to activate cell-signaling cascades similar to NMDARs suggests that nAChRs could interact with or perform a similar function to NMDARs during learning. To test whether nAChRs and NMDARs mediate similar processes, a dose of MK-801 subthreshold for disrupting fear conditioning $(0.05 \mathrm{mg} / \mathrm{kg}$, dose based on dose-response experiment) either alone or in combination with mecamylamine $(1.0 \mathrm{mg} / \mathrm{kg})$ was administered. A oneway ANOVA revealed an overall effect of treatment condition $\left[F_{(3,36)}=9.20, P<0.05\right]$. Post-hoc analysis revealed significant differences between saline pre-exposed and saline non-preexposed $(P<0.05)$ mice, indicating latent inhibition was established (Fig. 2). MK-801 pre-exposed mice were not significantly different from saline pre-exposed mice $(P>0.05)$ and were significantly different from non-pre-exposed mice $(P<0.05)$. These data suggest that this dose of MK-801 was ineffective at disrupting latent inhibition (Fig. 2). If the coadministration of MK-801 and mecamylamine disrupts latent inhibition, we would then expect these mice to demonstrate suppression ratios similar to

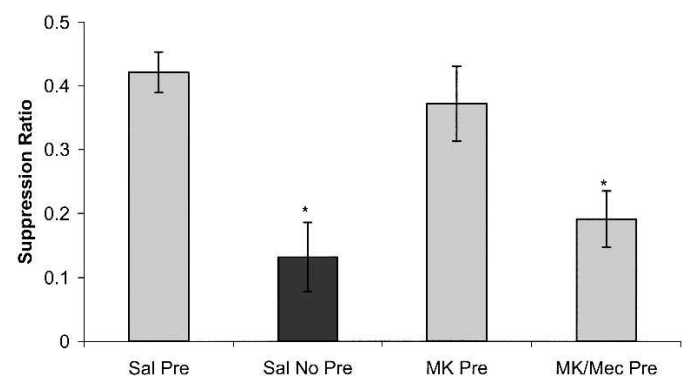

Figure 2. The effects of MK-801 (0.05 mg/kg; NMDAR antagonist), mecamylamine $(1.0 \mathrm{mg} / \mathrm{kg} ; \mathrm{nAChR}$ antagonist), or coadministration of the two drugs on latent inhibition of cued fear conditioning. There were significant differences between saline pre-exposed (Sal Pre) and saline non-pre-exposed (Sal No Pre) mice, indicating that latent inhibition was established. The coadministration of MK-801 and mecamylamine on preexposure day (MK/Mec Pre) blocked latent inhibition of cued fear conditioning. Light gray bars represent pre-exposed groups. Dark gray bars represent non-pre-exposed groups. Error bars, \pm SEM. $\left({ }^{*}\right)$ Significantly different from saline pre-exposed mice. 
saline non-pre-exposed mice and significantly different from saline pre-exposed mice. Post-hoc analysis revealed that the group that received both antagonists demonstrated suppression ratios that were not different form saline non-pre-exposed mice $(P>0.05)$ and were significantly lower than saline pre-exposed mice $(P<0.05)$, demonstrating that the coadministration of MK801 and mecamylamine disrupted latent inhibition of cued fear conditioning (Fig. 2). There was a significant effect of drug on latency to first lick $\left[F_{(3,36)}=5.89, P<0.05\right]$. The MK-801 preexposed mice demonstrated longer latency to initiate the first lick on testing day $(P<0.05$ for all comparisons). However, these mice demonstrated suppression ratios similar to saline preexposed mice, suggesting that this difference had little effect on the resulting suppression ratios on testing day.

\section{Experiment 3: AMPA/nAChR interaction in fear conditioning}

To examine the role of nAChRs and AMPARs in fear conditioning, mecamylamine alone, NBQX alone, or both drugs together were administered prior to training. It was expected that neither mecamylamine nor NBQX would block cued or contextual fear conditioning (Lu and Wehner 1997; Gould and Wehner 1999b), but coadministration of the two drugs would block contextual fear conditioning if AMPARs and nAChRs mediate similar processes involved in contextual conditioning. A one-way analysis of variance examining baseline freezing on training day revealed no differences between groups $\left[F_{(5,41)}=0.51, P>0.05\right]$ (Fig. 3). A one-way analysis of variance performed on freezing to the context on testing day revealed an overall effect of drug $\left[F_{(5,41)}=5.01, P<0.01\right]$. Post-hoc analysis revealed significant differences between the saline group and both of the mecamylamine and NBQX coadministration groups for contextual conditioning ( $P<0.05$ for both groups) (Fig. 3).

In addition to examining changes in contextual conditioning, changes in cued fear conditioning were also examined. A one-way analysis of variance performed on pre-CS freezing scores revealed no significant differences between groups $\left[F_{(5,41)}=2.32\right.$, $P>0.05]$, suggesting no differences in generalized freezing. A one-way analysis of variance performed on freezing during the CS revealed no significant differences between groups $\left[F_{(5,41)}=1.99, P>0.05\right]$ (Fig. 4$)$; suggesting that mice coadminis-

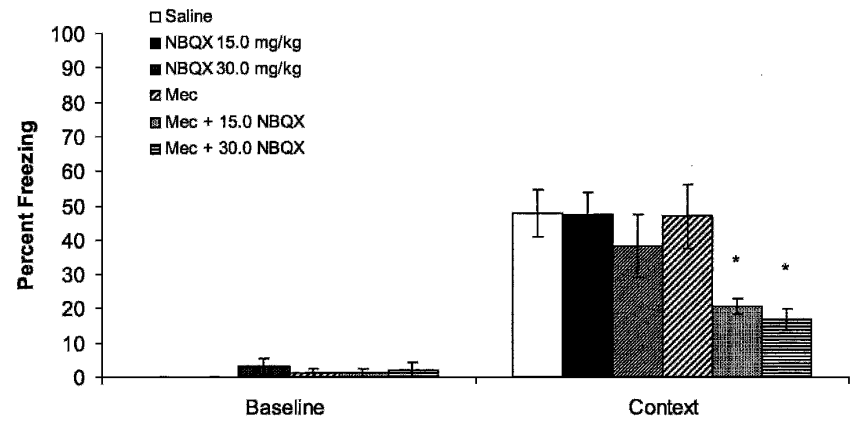

Figure 3. The effects of NBQX (15.0 and $30.0 \mathrm{mg} / \mathrm{kg})$, mecamylamine $(1.0 \mathrm{mg} / \mathrm{kg})$, or the coadministration of the two drugs on contextual fear conditioning. There were no differences in baseline freezing on training day for any of the groups. Neither NBQX nor mecamylamine administered alone had any effect on contextual fear conditioning on testing day when compared with saline controls. However, the coadministration of $1.0 \mathrm{mg} / \mathrm{kg}$ mecamylamine with $15.0 \mathrm{mg} / \mathrm{kg}$ or $30 \mathrm{mg} / \mathrm{kg} \mathrm{NBQX}$ on training day significantly reduced contextual fear conditioning on testing day compared with saline controls, and to mice administered either drug administered alone. Error bars, \pm SEM. (*) Significantly different from saline, NBQX $15 \mathrm{mg} / \mathrm{kg}, \mathrm{NBQX} 30 \mathrm{mg} / \mathrm{kg}$, and Mecamylamine.

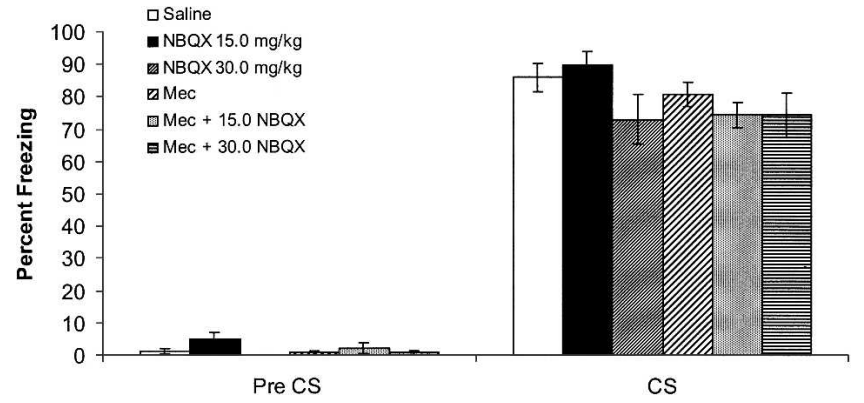

Figure 4. The effects of NBQX (15.0 mg/kg and $30.0 \mathrm{mg} / \mathrm{kg})$, mecamylamine $(1.0 \mathrm{mg} / \mathrm{kg})$, or the coadministration of both drugs on cued fear conditioning. There was no difference in pre-CS freezing between groups, and there was no significant effect of drug on freezing to the CS on testing day. Error bars, \pm SEM.

tered mecamylamine and NBQX can process the CS and form a CS association with the footshock US.

To examine the possibility that freezing to the CS in the $\mathrm{NBQX} / \mathrm{Mec}$ group was a result of nonassociative processes, mice received either saline or coadministration of mecamylamine and NBQX, and then received two presentations of the CS without the US. It was expected that these mice would not show fear to the context nor to the CS during subsequent tests. There were no differences between baseline freezing $\left[F_{(1,6)}=0.273, P>0.05\right]$, freezing to the context $\left[F_{(1,6)}=0.429, P>0.05\right]$, or freezing to the CS $\left[F_{(1,6)}=0.097, P>0.05\right]$ between groups (data not shown). These data suggest that freezing to the CS on testing day observed in mice coadministered mecamylamine and NBQX and trained in fear conditioning with CS-US pairings reflected the formation of a CS-US association.

\section{Experiment 4: NMDA/nAChR interactions in fear conditioning}

To further test whether nAChRs and NMDARs mediate similar processes during learning, we administered a subthreshold dose of MK-801 $(0.05 \mathrm{mg} / \mathrm{kg})$ either alone or in combination with mecamylamine $(1.0 \mathrm{mg} / \mathrm{kg})$. A one-way analysis of variance examining baseline freezing on training day revealed no differences between groups $\left[F_{(3,36)}=0.22, P>0.05\right]$ (Fig. 5). A one-way analysis of variance performed on freezing to the context on testing day revealed an overall effect of drug $\left[F_{(3,36)}=21.72, P<0.01\right]$. Post-hoc analysis revealed significant differences between the saline group and the MK-801/mecamylamine coadministration group $(P<0.05)$. No differences were observed between the saline and MK-801 alone groups, demonstrating that this dose of MK-801 was subthreshold for disrupting contextual fear conditioning. These results suggest that nAChRs may mediate similar processes as NMDARs during contextual fear conditioning.

To ensure that the deficits in contextual fear conditioning did not result from state-dependent effects, MK-801 and mecamylamine were also coadministered on both training and testing days. Post-hoc analysis revealed a significant difference in freezing to the context between the saline group and group that received MK-801 and mecamylamine at both training and testing groups $(P<0.05)$. There was no difference in contextual fear conditioning between mice that received MK-801 and mecamylamine only at training and mice that received MK-801and mecamylamine at both training and testing. Thus, no state-dependent effects were seen.

In addition to examining changes in contextual conditioning, changes in cued fear conditioning were also examined. A one-way analysis of variance performed on pre-CS freezing scores revealed no significant differences between groups $\left[F_{(3,36)}=0.88\right.$, 


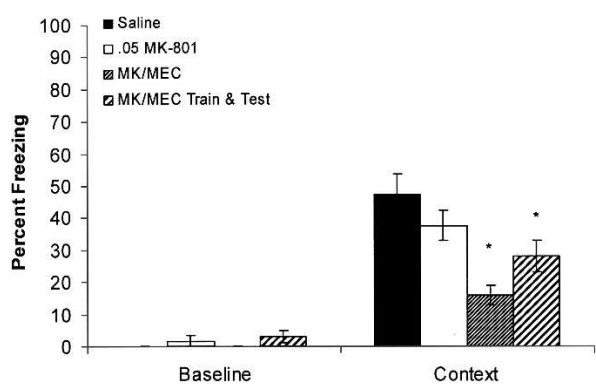

Figure 5. The effects of MK-801 $(0.05 \mathrm{mg} / \mathrm{kg})$, or the coadministration (at either training day only or both training and testing) of MK-801 and mecamylamine $(1.0 \mathrm{mg} / \mathrm{kg})$ on contextual fear conditioning. There were no differences in baseline freezing on training day for any of the groups. MK-801 administered alone had no effect on contextual fear conditioning compared with saline controls. However, the coadministration of 1.0 $\mathrm{mg} / \mathrm{kg}$ mecamylamine with $0.05 \mathrm{mg} / \mathrm{kg}$ MK-801 on training day, or on both training day and testing day, significantly reduced contextual fear conditioning on testing day compared with saline controls. Error bars, \pm SEM. (*) Significantly different from saline.

$P>0.05]$, suggesting no differences in generalized freezing. A one-way analysis of variance performed on freezing during the CS revealed a significant effect of drug $\left[F_{(3,36)}=10.42, P<0.05\right]$ (Fig. 6). Post-hoc analysis revealed that the saline group did not differ from either the MK-801 group or the MK-801/ mecamylamine coadministration group. However, the MK-801/ mecamylamine training/testing group showed significantly less fear to the CS than the saline group.

\section{Discussion}

There are four major findings from this study. First, we replicate previous results demonstrating that neither mecamylamine nor NBQX administered alone alter cued fear conditioning or contextual fear conditioning (Lu and Wehner 1997; Gould and Wehner 1999b). Second, we show that NBQX administration does not disrupt latent inhibition of cued fear conditioning, and we replicated previous research indicating that mecamylamine does not disrupt latent inhibition of cued fear conditioning (Gould et al. 2001). Third, we demonstrate for the first time that coadministration of mecamylamine and NBQX, at doses that produce no effects when administered alone, disrupts both contextual fear conditioning and latent inhibition of cued fear conditioning, but have little effect on cued fear conditioning. Fourth, we demonstrate for the first time that coadministration of mecamylamine and MK-801, at doses that produce no effect when administered alone, disrupts both contextual fear conditioning and latent inhibition of cued fear conditioning, but has little effect on cued fear conditioning. Because coadministration of either mecamylamine and NBQX or mecamylamine and MK-801 disrupted contextual but not cued fear conditioning, it cannot be argued that coadministration is altering locomotor activity or produces generalized deficits.

\section{$\mathrm{nAChR}$ and glutamate receptor interaction}

Our results provide the first behavioral evidence that coantagonism of nAChRs and glutamate receptors (either AMPARs or NMDARs) can block contextual fear conditioning and latent inhibition of cued fear conditioning. These findings suggest that nAChRs may mediate processes that support contextual fear conditioning and latent inhibition of cued fear conditioning that are similar or parallel to processes mediated by AMPARs and NMDARs. It is clear that NMDARs are involved in both contextual fear conditioning and latent inhibition of cued fear conditioning (Kim et al. 1991; Fanselow and Kim 1994; Fanselow et al.
1994; Stiedl et al. 2000; Gould et al. 2002; Lewis and Gould 2004). One possible mechanism through which AMPARs and nAChRs could contribute to acquisition of these tasks is by contributing to the membrane depolarization necessary for activating NMDAR-mediated processes. In support, nicotine can mediate synaptic current changes independent of glutamate receptors and can mediate postsynaptic events (Zhang et al. 1996; Roerig et al. 1997; Alkondon et al. 1998; Frazier et al. 1998a,b; Hefft et al. 1999; Chu et al. 2000; Ji et al. 2001). In addition, nAChRs have been localized on postsynaptic densities (Fabian-Fine et al. 2001; Levy and Aoki 2002). These findings suggest that nAChRs can support some fast excitatory synaptic transmission in the absence of glutamate and could play a significant role in NMDARdependent synaptic plasticity by contributing to the concurrent membrane depolarization necessary for NMDAR function. If, as our results suggest, nAChRs and AMPARs mediate similar processes, it might be expected that these receptors are colocalized. Levy and Aoki (2002) found that the majority of AMPAR-positive neurons in cortex were also nAChR positive in the postsynaptic densities. Thus, it is possible that antagonism of AMPARs does not disrupt contextual fear conditioning or latent inhibition of cued fear conditioning, because nAChRs are mediating similar cellular processes and vice-versa.

Nicotinic AchRs may contribute to learning-related neural changes by contributing to NMDAR activation through depolarizing a neuron and/or by directly activating cell-signaling cascades that are also activated by NMDARs during learning. In support, nicotine can enhance NMDAR-mediated processes (Aramakis and Metherate 1998). Specifically, nicotine can activate ERK/MAPK, CaMKII/IV, and CREB (Chang and Berg 2001; Nakayama et al. 2001; Berg and Conroy 2002; Dajas-Bailador et al. 2002b; Utsugisawa et al. 2002; Brunzell et al. 2003). Activation of these cell-signaling cascades mediated through nAChRs could contribute to contextual fear conditioning and latent inhibition of cued fear conditioning.

\section{Cued fear conditioning}

Interestingly, our results suggest a differential effect of coadministration of NBQX and mecamylamine between contextual fear conditioning and cued fear conditioning; cued fear conditioning appears to be less sensitive to the effects of both drugs. Coadministration of NBQX and mecamylamine resulted in a $>60 \%$ reduction in contextual fear conditioning, while cued fear conditioning was reduced by only $15 \%$. The reasons for the difference in the effects of coadministration of mecamylamine and NBQX be-

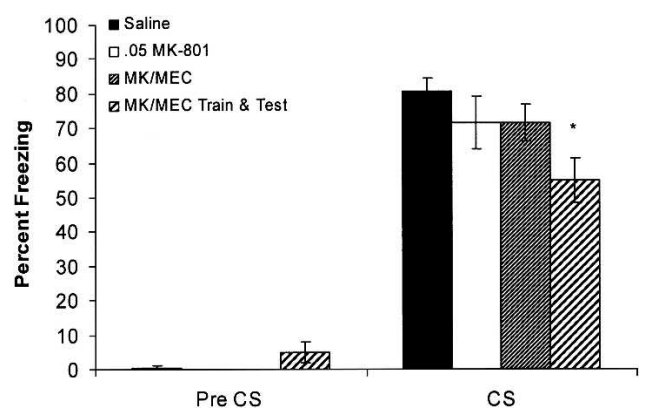

Figure 6. The effects of MK-801 $(0.05 \mathrm{mg} / \mathrm{kg})$, or the coadministration (at either training day only or both training and testing) of MK-801 and mecamylamine $(1.0 \mathrm{mg} / \mathrm{kg})$ on cued fear conditioning. There was no difference in pre-CS freezing between groups, but there was a significant effect of drug on freezing to the CS on testing day. The effect was due to reduced freezing in the group that received MK-801 and mecamylamine at both training and testing. Error bars, \pm SEM. $\left(^{*}\right)$ Significantly different from saline. 
tween cued fear conditioning and contextual fear conditioning may be related to differences in brain areas involved and neurotransmitter systems involved. For instance, contextual fear conditioning, but not cued fear conditioning, depends on the hippocampus (Kim and Fanselow 1992; Phillips and LeDoux 1992; Kim et al. 1993; Logue et al. 1997). Thus, nAChRs and AMPARs in the hippocampus may be involved in contextual fear conditioning, but different receptors in another area may support cued fear conditioning.

It is possible that for cued fear conditioning, AMPARs and another receptor type mediate similar processes, and thus, NBQX was without significant effect on cued fear conditioning. It should be pointed out that cued fear conditioning was reduced by $15 \%$ by administration of NBQX alone. Although this decrease in freezing to the CS was not significant, the change suggests that AMPARs may be involved in cued fear conditioning. In support, the AMPAR-facilitating drug BDP-12 enhanced acquisition of cued fear conditioning (Rogan et al. 1997). Furthermore, AMPARs have been shown to be involved in fear potentiated startle (Walker and Davis 1997).

Not surprisingly, administration of $0.05 \mathrm{mg} / \mathrm{kg}$ MK-801, the dose chosen because it was subthreshold for disrupting fear conditioning, did not disrupt cued fear conditioning when administered alone or with mecamylamine on training day. However, coadministration of mecamylamine and MK-801 at both training and testing disrupted cued fear conditioning. These data could suggest that nAChRs and NMDARs interact during recall of cued fear. Clearly, the issues of nAChR and glutamate receptor interactions during consolidation and recall need further examination.

\section{AMPARS: Acquisition and consolidation}

Our finding that NBQX alone has no effect on contextual fear conditioning and latent inhibition supports previous studies that report no learning-related memory impairments associated with AMPAR antagonism by NBQX (Parada et al. 1992; Misztal and Danysz 1995; Stephens and Cole 1996; Lu and Wehner 1997; Filliat et al. 1998; Mead and Stephens 1999; Pitsikas et al. 2002; Willmore et al. 2002; Gutierrez et al. 2004), even though NBQX has a high affinity for AMPARs and inhibits glutamate and AMPA-associated currents (Sheardown et al. 1990; Parsons et al. 1994; Rammes et al. 1998). However, it should be noted that some behavioral tasks have been shown to be sensitive to the AMPA/kainate receptor antagonist CNQX. These effects of AMPA/kainate receptor antagonism may be related to the effects of CNQX on consolidation, retention, or recall. Post-training administration of CNQX disrupted consolidation, retention, or recall of several learning tasks (Danysz and Wroblewski 1989; Flood et al. 1990; Kim et al. 1993; Quillfeldt et al. 1994; Mesches et al. 1996; Attwell et al. 1999; Izquierdo et al. 2000; Vianna et al. 2000; Yasoshima et al. 2000; Bonini et al. 2003; Day et al. 2003). Thus, AMPARs may have a greater role in post-acquisition learningrelated phenomena. A post-acquisition role for AMPARs fits well with LTP studies that show trafficking of AMPARs post LTP tetanus (for review, see Sheng and Kim 2002; Bredt and Nicoll 2003).

\section{AMPAR antagonist selectivity}

A contributing factor to differences seen in the effects of AMPAR antagonism on learning may also be the selectivity of the antagonists used. Sheardown et al. (1990) compared the pharmacological properties of NBQX, CNQX, and DNQX. Their results indicate that NBQX has an affinity for AMPARs $\left(\mathrm{IC}_{50}=0.15 \mu \mathrm{m}\right.$; $\mathrm{IC}_{50}=$ inhibition concentration-concentration required to reduce radioligand binding to half of maximal value) that is two times greater than CNQX $\left(\mathrm{IC}_{50}=0.3 \mu \mathrm{m}\right)$ and over three times greater than DNQX $\left(\mathrm{IC}_{50}=0.5 \mu \mathrm{m}\right)$. Importantly, NBQX also shows a threefold lower affinity for kainate receptors $\left(\mathrm{IC}_{50}=4.8 \mu \mathrm{m}\right)$ than CNQX $\left(\mathrm{IC}_{50}=1.5 \mu \mathrm{m}\right)$ and over a twofold lower affinity than DNQX $\left(\mathrm{IC}_{50}=2.0 \mu \mathrm{m}\right)$. In addition, NBQX shows very low affinity for NMDARs $\left(\mathrm{IC}_{50}>90 \mu \mathrm{m}\right)$ and glycine receptors $\left(\mathrm{IC}_{50}>100 \mu \mathrm{m}\right)$ unlike CNQX ( $\mathrm{IC}_{50}=25 \mu \mathrm{m}-\mathrm{NMDA} ; \mathrm{IC}_{50}=14 \mu \mathrm{m}$-glycine $)$ and DNQX $\left(\mathrm{IC}_{50}=40 \mu \mathrm{m}-\mathrm{NMDA} ; \mathrm{IC}_{50}=9.5 \mu \mathrm{m}\right.$-glycine $)$, which show higher affinity for those receptors. Interestingly, inhibitory avoidance conditioning of bead pecking in the chick has been shown to be disrupted by direct infusion of CNQX, but not by direct infusion of NBQX (Burchuladze and Rose 1992; Rickard et al. 1994). Further, NBQX and another selective AMPAR antagonist, GYKI 52366, did not block LTP (Sato et al. 1995; Kapus et al. 2000). Another study, (Svendsen et al. 1999), reported only partial attenuation of LTP by NBQX; an $\sim 20 \%$ reduction in LTP at $1.5 \mathrm{~h}$ post-tetanus that returned to levels of LTP that were equal to levels in the drug-free condition by $2 \mathrm{~h}$ post-tetanus. However, it has been reported that CNQX disrupted induction of LTP (Debray et al. 1997). Thus, the possibility exists that disruption of LTP and learning tasks by CNQX could be related to effects of the drug at kainate receptors, and possibly NMDA or glycine receptors, as well as at AMPARs. Evidence indicates an increasingly important role for kainate and glycine receptors in some forms of synaptic plasticity (Danysz and Wroblewski 1989; Lerma 2003).

\section{Summary}

In conclusion, we found, as have others, that AMPAR antagonism did not disrupt learning. Furthermore, the present study demonstrated that learning was disrupted when AMPAR antagonism occurred concurrently with nAChR antagonism and when NMDAR antagonism occurred concurrently with nAChR antagonism. We propose a model of learning-related synaptic plasticity in which both AMPARs and nAChRs can contribute to depolarization necessary for activating NMDAR-mediated processes. AMPARs could primarily be involved in mediating this depolarization and nAChRs could facilitate the depolarization. The facilitation by $\mathrm{nAChR}$ activation could be equivalent to behavioral states that enhance learning, such as increased attention. This fits well with studies and theories of learning and attention that propose an involvement of AChRs in these processes (for review, see Levin and Simon 1998; Hasselmo 1999; Gold 2003; Tinsley et al. 2004). Moreover, for acquisition of behaviors that involve neural areas with high cholinergic activity, such as the hippocampus (Marks et al. 1989; Hasselmo 1999; Fadda et al. 2000), antagonism of AMPARs may not produce significant effects, because processes mediated by nAChRs may compensate. Thus, activation of NMDARs may be a critical event for some types of learning, but multiple receptor types could mediate the membrane depolarization necessary for NMDAR activation. Once activated, the NMDAR-mediated processes may lead to changes in synaptic plasticity through mechanisms such as insertion of AMPARs into the cell membrane (for review, see Bredt and Nicoll 2003). In addition, increased calcium influx mediated by nAChRs (Eilers et al. 1997; Wonnacott 1997; Sorenson et al. 1998; Broide and Leslie 1999; Porter et al. 1999; Nomikos et al. 2000; Berg and Conroy 2002; Dajas-Bailador et al. 2002a; Perry et al. 2002) may not only contribute to the depolarization necessary for activation of NMDARs during learning, but may also facilitate NMDAR-mediated processes involved in learning by directly activating cell signaling cascades involved in learning.

\section{Materials and Methods}

\section{Subjects}

Male C57BL/6J ( $n=7-9$ per group, except for the no-shock condition, where $n=4$ for both groups) mice were obtained from

\section{Learning \& Memory}


The Jackson Laboratory. A previous strain survey on latent inhibition of cued fear conditioning found that C57BL/6 mice strongly developed latent inhibition of cued fear conditioning compared with other strains of mice (Gould and Wehner 1999a). In addition, C57BL/6J mice have been used extensively for research on the effects of nicotine on fear conditioning and latent inhibition of cued fear conditioning (Gould and Wehner 1999a; Gould et al. 2001; Gould 2003; Gould and Higgins 2003; Gould and Lommock 2003; Gould et al. 2004). Mice that were fear conditioned were group housed and had ad libitum access to Purina Rodent Diet and water. Mice trained in latent inhibition had ad libitum access to food and water prior to training. During latent inhibition training, mice were water restricted, but received daily water during all phases. Body weight was measured daily, and no mice fell below $80 \%$ of free-drinking weight. The light-dark cycle was 12:12 with lights on at 7:00 a.m. and all testing occurred between 9:00 a.m. and 5:00 p.m. Mice were tested between 8 and $16 \mathrm{wk}$ of age, and mice were not used in multiple experiments. All behavioral procedures were approved by the Temple University Institutional Animal Care and Use Committee.

\section{Apparatus}

All behavioral procedures for latent inhibition and training for fear conditioning occurred in four identical conditioning chambers $(7 \times 7.5 \times 15$ in) housed in sound attenuating boxes (Med Associates). Ventilation fans at the rear of the boxes offered air exchange and background noise $(69 \mathrm{~dB})$. The conditioning chambers were constructed of clear Plexiglass walls in the front and back, and stainless steel on the sides. Grid floors were connected to a shock scrambler and generator. A speaker mounted to the outside right wall of each chamber produced the 85-dB white noise CS. Sipper tubes were present on the left side of each chamber. An IBM-PC compatible computer running MED-PC software interfaced with the conditioning chamber to control access to the sipper tubes via a mechanized sliding door, stimuli administration, and record licks from the sipper tube for latent inhibition.

The CS test for cued fear conditioning occurred in a different room with altered conditioning chambers $(8 \times 9 \times 7.5$ in $)$ of different size and shape. Covering the metal grid floor with a flat plastic floor and the presence of a vanilla extract olfactory cue further altered these chambers. Ventilation fans $(70 \mathrm{~dB})$ were located at the rear of the boxes. The speaker was mounted to the left outside wall and generated an 85-dB white noise CS. All chambers were cleaned with $70 \%$ ethanol before each use.

\section{Behavioral procedures: Latent inhibition}

The day before the procedure began, mice were weighed and marked. The mice were placed on water restriction, as lick suppression was the dependent variable. The procedure consisted of five phases conducted over an 8-d period and is based on previous research examining latent inhibition of cued fear conditioning (Gould and Wehner 1999b; Gould et al. 2001; Lewis and Gould 2004).

\section{Pre-training phase: Days 1-4}

Mice were placed in chambers, and the session began with the opening of the sipper-tube doors. The mice had free access to the sipper tubes for $15 \mathrm{~min}$ each day throughout this phase, and the computer recorded the number of licks. Asymptotic licking levels were achieved by the fourth day.

\section{Pre-exposure phase: Day 5}

Pre-exposed mice were placed in the chambers and no stimuli were presented during the first $15 \mathrm{sec}$. Following the first $15 \mathrm{sec}$, mice were exposed to 20, 5-sec CS presentations of 85-dB white noise with a fixed 15-sec interstimulus interval between CS presentations. The session ended with $15 \mathrm{sec}$ of no stimulus presentations before the mice were removed from the chambers. The duration of the pre-exposure phase was $7 \mathrm{~min}$. Non-pre-exposed control mice were exposed to the chamber for the same duration, but they received no exposure to the white noise. Mice did not have access to sipper tubes during this phase to avoid any possible secondary associations that could form between the CS and access to sipper tubes. Water was administered after the session and the mice were weighed.

\section{Training phase: Day 6}

All mice were placed in the chambers, and 2.5 min elapsed before the first CS-US pairing. The first CS ( $85 \mathrm{~dB}$ white noise, $5 \mathrm{sec}$ in duration)-US (1 sec, $0.57 \mathrm{~mA}$ footshock) pairing was followed by a 2.5-min intertrial interval prior to the second pairing. The mice were removed $2 \mathrm{~min}$ after the final CS-US presentation. The duration of the training session was $7 \mathrm{~min}$. Mice were not allowed access to sipper tubes during this phase to avoid any possible secondary associations that could form between access to sipper tubes and the US. After the session ended, water was administered and the mice were weighed.

\section{Re-establish licking phase: Day 7}

Because sipper tubes were not present on days 5 and 6, day 7 was used to re-establish licking behavior in the chambers prior to testing. Mice were placed in the chambers and allowed access to sipper tubes as in the pre-training phase. The average number of licks on this day was 800 , indicating a high level of licking behavior.

\section{Testing phase: Day 8}

All mice were placed in chambers, and each session initiated with the first lick by each mouse. The time from the onset of the chamber lights to initiate the first lick of the testing session was recorded to compare latency with first lick across groups. At lick 81 , the time to complete licks 81-90 was recorded. At lick 91, presentation of the CS occurred until lick 100, and the time to complete licks 91-100 was recorded. Freezing was measured as a suppression of licking behavior. This data was transformed into a suppression ratio. The ratio is represented by the formula $A / A+B$. The time to complete licks 81-90 (A) divided by the time to complete licks 81-90 (A) + licks 91-100 (B). Latent inhibition indicates a lower expression of conditioned fear, and thus, the time to complete the 10 licks prior to CS presentation should be equivalent to the time to complete the 10 licks during CS presentation. For example, 1 sec for licks $81-90 / 1$ sec for $81-90+1$ sec for licks $91-100=0.50$. A greater time to complete 10 licks during CS presentation is indicative of greater conditioned fear, and this will result in the suppression ratio approaching zero. For example, 1 sec for licks $81-90 / 1$ sec for licks $81-90+99$ sec for licks $91-100=0.01$.

\section{Behavioral procedures: Fear conditioning}

The procedure is the same as described in Gould and Higgins (2003). The day before training, mice were weighed and marked. On training day, mice were given injections and then placed in a conditioning chamber. Training lasted $5 \mathrm{~min}$ and $30 \mathrm{sec}$. Baseline freezing was established for the first 120 sec using a timesampling procedure, in which mice were determined to be either freezing or moving once every $10 \mathrm{sec}$. Freezing was defined as the total lack of movement except for respiration, as described in Blanchard and Blanchard (1969). The first auditory CS (85 dB white noise) was presented at $120 \mathrm{sec}$ and lasted for $30 \mathrm{sec}$. During the last $2 \mathrm{sec}$ of the auditory CS, the shock US $(0.57 \mathrm{~mA})$ was presented. During the 120 -sec intertrial interval, freezing before the next CS-US pairing was scored. The mice remained in the cage for $30 \mathrm{sec}$ after termination of the second CS-US pairing.

Testing occurred $\sim 24 \mathrm{~h}$ after training. Mice were placed into the original training context and freezing was scored continuously for $5 \mathrm{~min}$. Approximately $1 \mathrm{~h}$ later, mice were placed into the altered context for $6 \mathrm{~min}$. Pre-CS freezing was measured for 3 min, during which no auditory CS was present. During the last 3 min, mice were continuously presented with the auditory CS and freezing was measured. 


\section{Drugs}

The AMPAR antagonist NBQX (15 mg/kg and $30 \mathrm{mg} / \mathrm{kg}$; Sigma Co.; doses based on previous research that found that both $30 \mathrm{mg} / \mathrm{kg}$ and $56 \mathrm{mg} / \mathrm{kg}$ did not affect contextual fear conditioning, as well as previous research that found ataxic side-effects of NBQX at doses above $30 \mathrm{mg} / \mathrm{kg}$ in C57BL/6 mice (Lu and Wehner 1997) was dissolved in $0.9 \%$ physiological saline. NBQX was administered by an intraperitoneal injection $30 \mathrm{~min}$ prior to behavioral procedures. The nAChR antagonist mecamylamine ( $1 \mathrm{mg} / \mathrm{kg}$ and $2 \mathrm{mg} / \mathrm{kg}$; Sigma; doses based on previous research; [Gould and Wehner 1999b; Gould et al. 2001; Gould and Higgins 2003]) was dissolved in physiological saline $(0.9 \% \mathrm{NaCl})$ and administered by an intraperitoneal injection $15 \mathrm{~min}$ prior to behavioral procedures. In an initial study, we found that coadministration of NBQX and $2 \mathrm{mg} / \mathrm{kg}$ of mecamylamine disrupted latent inhibition $\left[F_{(3,27)}=9.43, P<0.01\right]$, but $2 \mathrm{mg} / \mathrm{kg}$ of mecamylamine had no effect on latent inhibition. Also, a previous study showed that $2 \mathrm{mg} / \mathrm{kg}$ mecamylamine had no effect on fear conditioning (Gould and Wehner 1999b). Thus, we tested whether a lower dose of mecamylamine coadministered with NBQX or MK-801 would disrupt latent inhibition and contextual fear conditioning. The data with $1 \mathrm{mg} / \mathrm{kg}$ of mecamylamine is reported in the Results section. The NMDAR antagonist MK-801 $(0.05 \mathrm{mg} / \mathrm{kg}$, a subthreshold dose for disrupting contextual fear conditioning based on a dose-response analysis; Sigma Co.) was dissolved in physiological saline $(0.9 \% \mathrm{NaCl})$ and administered by an intraperitoneal injection $15 \mathrm{~min}$ prior to behavioral procedures. The number of injections was equalized across all groups.

\section{Statistical analysis}

One-way analyses of variance were performed on suppression ratios and lick latency data for the latent inhibition experiment. One-way analyses of variance were performed on percent freezing scores for baseline, contextual freezing, pre-CS, and CS data. Tukey HSD analyses were performed, post-hoc, to detect differences at the $P<0.05$ level. Analyses were performed via SPSS version 11.5 .

\section{Acknowledgments}

We acknowledge grant support from the American Federation for Aging Research (T.G.), the Pennsylvania Department of Health (T.G.), and Temple University (T.G.).

\section{References}

Alkondon, M. and Albuquerque, E.X. 2002. A non- $\alpha 7$ nicotinic acetylcholine receptor modulates excitatory input to hippocampal CA1 interneurons. J. Neurophys. 87: 1651-1654.

Alkondon, M., Rocha, E.S., Maelicke, A., and Albuquerque, E.X. 1996. Diversity of nicotinic acetylcholine receptors in rat brain. $\alpha$-bungarotoxin-sensitive nicotinic receptors in olfactory bulb neurons and presynaptic modulation of glutamate release. J. Pharmacol. Exp. Ther. 278: 1460-1471.

Alkondon, M., Pereira, E.F.R., Barbosa, C.T.F., and Albuquerque, E.X. 1997. Neuronal nicotinic acetylcholine receptor activation modulates $\gamma$-aminobutyric acid release from CA1 neurons of rat hippocampal slices. J. Pharmacol. Exp. Ther. 283: 1396-1411.

Alkondon, M., Pereira, E.F., and Albuquerque, E.X. 1998. $\alpha$-bungarotoxin- and methyllycaconitine-sensitive nicotinic receptors mediate fast synaptic transmission in interneurons of rat hippocampal slices. Brain Res. 810: 257-263.

Aramakis, V.B. and Metherate, R. 1998. Nicotine selectively enhances NMDA receptor-mediated synaptic transmission during postnatal development in sensory neocortex. J. Neurosci. 18: 8485-8495.

Attwell, P.J., Rahman, S., Ivarsson, M., and Yeo, C.H. 1999. Cerebellar cortical AMPA-kainate receptor blockade prevents performance of classically conditioned nictitating membrane responses. J. Neurosci. 19: RC45.

Aultman, J.M. and Moghaddam, B. 2001. Distinct contributions of glutamate and dopamine receptors to temporal aspects of rodent working memory using a clinically relevant task. Psychopharmacology 153: $353-364$.
Berg, D.K. and Conroy, W.G. 2002. Nicotinic $\alpha 7$ receptors: Synaptic options and downstream signaling in neurons. J. Neurobiol. 53: 512-523.

Blanchard, R.J. and Blanchard, D.C. 1969. Passive and active reactions to fear-eliciting stimuli. J. Comp. Physiol. Psychol. 68: 129-135.

Bonini, J.S., Rodrigues, L., Kerr, D.S., Bevilaqua, L.R., Cammarota, M., and Izquierdo, I. 2003. AMPA/kainate and group-I metabotropic receptor antagonists infused into different brain areas impair memory formation of inhibitory avoidance in rats. Behav. Pharmacol. 14: $161-166$.

Braff, D.L. 1993. Information processing and attention dysfunctions in schizophrenia. Schizophr. Bull. 19: 233-259.

Bredt, D.S. and Nicoll, R.A. 2003. AMPA receptor trafficking at excitatory synapses. Neuron 40: 361-379.

Broide, R.S. and Leslie, F.M. 1999. The $\alpha 7$ nicotinic acetylcholine receptor in neuronal plasticity. Mol. Neurobiol. 20: $1-16$.

Brunzell, D.H., Russell, D.S., and Picciotto, M.R. 2003. In vivo nicotine treatment regulates mesocorticolimbic CREB and ERK signaling in C57Bl/6J mice. J. Neurochem. 84: 1431-1441.

Burchuladze, R. and Rose, S.P. 1992. Memory formation in day-old chicks requires NMDA but not non-NMDA glutamate receptors. Eur. J. Neurosci. 4: 533-538.

Caldarone, B.J., Duman, C.H., and Picciotto, M.R. 2000. Fear conditioning and latent inhibition in mice lacking the high affinity subclass of nicotinic acetylcholine receptors in the brain. Neuropharmacology 39: 2779-2784.

Chang, K.T. and Berg, D.K. 2001. Voltage-gated channels block nicotinic regulation of CREB phosphorylation and gene expression in neurons. Neuron 32: 855-865.

Chu, Z.G., Zhou, F.M., and Hablitz, J.J. 2000. Nicotinic acetylcholine receptor-mediated synaptic potentials in rat neocortex. Brain Res. 887: 399-405.

Dajas-Bailador, F.A., Mogg, A.J., and Wonnacott, S. 2002a. Intracellular $\mathrm{Ca}^{2+}$ signals evoked by stimulation of nicotinic acetylcholine receptors in SH-SY5Y cells: Contribution of voltage-operated $\mathrm{Ca}^{2+}$ channels and $\mathrm{Ca}^{2+}$ stores. J. Neurochem. 81: 606-614.

Dajas-Bailador, F.A., Soliakov, L., and Wonnacott, S. 2002b. Nicotine activates the extracellular signal-regulated kinase $1 / 2$ via the $\alpha 7$ nicotinic acetylcholine receptor and protein kinase $\mathrm{A}$, in $\mathrm{SH}-$ SY5Y cells and hippocampal neurones. J. Neurochem. 80: 520-530.

Danysz, W. and Wroblewski, J.T. 1989. Amnesic properties of glutamate receptor antagonists. Neurosci. Res. Commun. 479: 9-18.

Danysz, W., Zajaczkowski, W., and Parsons, C.G. 1995. Modulation of learning processes by ionotropic glutamate receptor ligands. Behav. Pharmacol. 6: 455-474.

Davis, J.A. and Gould, T.J. 2005. Rolipram attenuates MK-801-induced deficits in latent inhibition. Behav. Neurosci. 119: 595-602.

Day, M., Langston, R., and Morris, R.G. 2003. Glutamate-receptor-mediated encoding and retrieval of paired-associate learning. Nature 424: 205209.

Debray, C., Diabira, D., Gaiarsa, J.L., Ben-Ari, Y., and Gozlan, H. 1997. Contributions of AMPA and GABA(A) receptors to the induction of NMDAR-dependent LTP in CA1. Neurosci. Lett. 238: 119-122.

Eilers, H., Schaeffer, E., Bickler, P.E., and Forsayeth, J.R. 1997. Functional deactivation of the major neuronal nicotinic receptor caused by nicotine and a protein kinase C-dependent mechanism. Mol. Pharmacol. 52: 1105-1112.

Escobar, M.L., Alcocer, I., and Bermudez-Rattoni, F. 2002. In vivo ffects of intracortical administration of NMDA and metabotropic glutamate receptors antagonists on neocortical long-term potentiation and conditioned taste aversion. Behav. Brain Res. 129: 101-106.

Fabian-Fine, R., Skehel, P., Errington, M.L., Davies, H.A., Sher, E., Stewart, M.G., and Fine, A. 2001. Ultrastructural distribution of the $\alpha 7$ nicotinic acetylcholine receptor subunit in rat hippocampus. J. Neurosci. 21: 7339-8003.

Fadda, F., Cocco, S., and Stancampiano, R. 2000. Hippocampal acetylcholine release correlates with spatial learning performance in freely moving rats. Neuroreport 11: 2265-2269.

Fanselow, M.S. and Kim, J.J. 1994. Acquisition of contextual Pavlovian fear conditioning is blocked by application of an NMDA receptor antagonist D,L-2-amino-5-phosphonovaleric acid to the basolateral amygdala. Behav. Neurosci. 108: 210-212.

Fanselow, M.S., Kim, J.J., Yipp, J., and De Oca, B. 1994. Differential effects of the $N$-methyl-D-aspartate antagonist DL-2-amino-5-phosphonovalerate on acquisition of fear of auditory and contextual cues. Behav. Neurosci. 108: 235-240.

Filliat, P., Pernot-Marino, I., Baubichon, D., and Lallement, G. 1998. Behavioral effects of NBQX, a competitive antagonist of the AMPA receptors. Pharmacol. Biochem. Behav. 59: 1087-1092.

Flood, J.F., Baker, M.L., and Davis, J.L. 1990. Modulation of memory 
processing by glutamic acid receptor agonists and antagonists. Brain Res. 521: 197-202.

Frazier, C.J., Buhler, A.V., Weiner, J.L., and Dunwiddie, T.V. 1998a Synaptic potentials mediated via $\alpha$-bungarotoxin-sensitive nicotinic acetylcholine receptors in rat hippocampal interneurons. J. Neurosci. 20: $8228-8235$.

Frazier, C.J., Rollins, Y.D., Breese, C.R., Leonard, S., Freedman, R., and Dunwiddie, T.V. 1998b. Acetylcholine activates an $\alpha$-bungarotoxin-sensitive nicotinic current in rat hippocampal interneurons, but not pyramidal cells. J. Neurosci. 18: 1187-1195.

Fujii, S. and Sumikawa, K. 2001. Acute and chronic nicotine exposure reverse age-related declines in the induction of long-term potentiation in the rat hippocampus. Brain Res. 894: 347-353.

Fujii, S., Ji, Z., Morita, N., and Sumikawa, K. 1999. Acute and chronic nicotine exposure differentially facilitate the induction of LTP. Brain Res. 846: 137-143.

Fujii, S., Jia, Y., Yang, A., and Sumikawa, K. 2000. Nicotine reverses GABAergic inhibition of long-term potentiation induction in the hippocampal CA1 region. Brain Res. 863: 259-265.

Gold, P.E. 2003. Acetylcholine modulation of neural systems involved in learning and memory. Neurobiol. Learn. Mem. 80: 194-210.

Gould, T.J. 2003. Nicotine produces a within subject enhancement of contextual fear conditioning in C57BL/6 mice independent of sex. Integ. Physiol. Behav. Sci. 38: 124-132.

Gould, T.J. and Higgins, J.S. 2003. Nicotine enhances contextual fear conditioning in C57BL/6J mice at 1 and 7 days post-training. Neurobiol. Learn. Mem. 80: 147-157.

Gould, T.J. and Lewis, M.C. 2003. Latent inhibition of cued fear conditioning is inhibited by co-antagonism of nicotinic and AMPA receptors but is not inhibited by antagonism of either receptor subtype alone. Abstract Viewer/Itinerary Planner, Program No. 721.1. Society for Neuroscience, Washington, DC.

Gould, T.J. and Lommock, J.A. 2003. Nicotine enhances contextual fear conditioning and ameliorates ethanol-induced deficits in contextual fear conditioning. Behav. Neurosci. 117: 1276-1282.

Gould, T.J. and Wehner, J.M. 1999a. Genetic influences on latent inhibition. Behav. Neurosci. 113: 1291-1296.

. 1999b. Nicotine enhancement of contextual fear conditioning. Behav. Brain Res. 102: 31-39.

Gould, T.J., Collins, A.C., and Wehner, J.M. 2001. Nicotine enhances latent inhibition and ameliorates ethanol-induced deficits in latent inhibition. Nicotine Tob. Res. 3: 17-24.

Gould, T.J., McCarthy, M.M., and Keith, R.A. 2002. MK-801 disrupts acquisition of contextual fear conditioning but enhances memory consolidation of cued fear conditioning. Behav. Pharmacol. 13: 287-294.

Gould, T.J., Feiro, O., and Moore, D. 2004. Nicotine enhancement of trace cued fear conditioning but not delay cued fear conditioning in C57BL/6J mice. Behav. Brain. Res. 155: 167-173.

Grady, S., Marks, M.J., Wonnacott, S., and Collins, A.C. 1992. Characterization of nicotinic receptor-mediated [H-3] dopamine release from synaptosomes prepared from mouse striatum. I. Neurochem. 59: 848-856.

Gray, J.A. 1998. Integrating schizophrenia. Schizophr. Bull. 24: 249-266.

Gutierrez, R., De la Cruz, V., Rodriguez-Ortiz, C.J., and Bermudez-Rattoni, F. 2004. Perirhinal cortex muscarinic receptor blockade impairs taste recognition memory formation. Learn. Mem. 11: 95-101.

Han, J.S., Gallagher, M., and Holland, P. 1995. Hippocampal lesions disrupt decrements but not increments in conditioned stimulus processing. J. Neurosci. 15: 7323-7329.

Hasselmo, M.E. 1999. Neuromodulation: Acetylcholine and memory consolidation. Trends Cogn. Sci. 3: 351-359.

He, J., Deng, C.Y., Chen, R.Z., Zhu, X.N., and Yu, J.P. 2000. Long-term potentiation induced by nicotine in CA1 region of hippocampal slice is $\mathrm{Ca}(2+)$-dependent. Acta. Pharmacol. Sin. 21: 429-432.

Hefft, S., Hulo, S., Bertrand, D., and Muller, D. 1999. Synaptic transmission at nicotinic acetylcholine receptors in rat hippocampal organotypic cultures and slices. J. Physiol. 515: 769-776.

Herron, C.E., Lester, R.A., Coan, E.J., and Collingridge, G.L. 1986 Frequency-dependent involvement of NMDA receptors in the hippocampus: A novel synaptic mechanism. Nature 322: 265-268.

Izquierdo, L.A., Barros, D.M., Ardenghi, P.G., Pereira, P., Rodrigues, C., Choi, H., Medina, J.H., and Izquierdo, I. 2000. Different hippocampal molecular requirements for short- and long-term retrieval of one-trial avoidance learning. Behav. Brain Res. 111: 93-98.

Ji, D., Lape, R., and Dani, J.A. 2001. Timing and location of nicotinic activity enhances or depresses hippocampal synaptic plasticity. Neuron 31: 131-141.

Kapus, G., Szekely, J.I., Durand, J., Ruiz, A., and Tarnawa, I. 2000. AMPA receptor antagonists, GYKI 52466 and NBQX, do not block the induction of long-term potentiation at therapeutically relevant concentrations. Brain Res. Bull. 52: 511-517.

Kaye, H. and Pearce, J.M. 1987. Hippocampal lesions attenuate latent inhibition and the decline of the orienting response in rats. Q. J. Exp. Psychol. B. 39: 107-125.

Kilts, C.D. 2001. The changing roles and targets for animal models of schizophrenia. Biol. Psych. 50: $845-855$.

Kim, J.J. and Fanselow, M.S. 1992. Modality-specific retrograde amnesia of fear. Science 256: 675-677.

Kim, J.J., DeCola, J.P., Landeira-Fernandez, J., and Fanselow, M.S. 1991. $\mathrm{N}$-methyl-D-aspartate receptor antagonist APV blocks acquisition but not expression of fear conditioning. Behav. Neurosci. 105: 126-133.

Kim, M., Campeau, S., Falls, W.A., and Davis, M. 1993. Infusion of the non-NMDA receptor antagonist CNQX into the amygdala blocks the expression of fear-potentiated startle. Behav. Neural. Biol. 59: 5-8.

Lees, G.J. 2000. Pharmacology of AMPA/kainate receptor ligands and their therapeutic potential in neurological and psychiatric disorders. Drugs 59: 33-78.

Lerma, J. 2003. Roles and rules of kainate receptors in synaptic transmission. Nat. Rev. Neurosci. 4: 481-495.

Levin, E.D. and Simon, B.B. 1998. Nicotinic acetylcholine involvement in cognitive function in animals. Psychopharmacology 138: 217-230.

Levy, R.B. and Aoki, C. 2002. Alpha7 nicotinic acetylcholine receptors occur at postsynaptic densities of AMPA receptor-positive and -negative excitatory synapses in rat sensory cortex. J. Neurosci. 22: 5001-5015.

Lewis, M.C. and Gould, T.J. 2004. Latent inhibition of cued fear conditioning: An NMDA receptor dependent process that can be established in the presence of anisomycin. Eur. J. Neurosci. 20: 818-826.

Li, H.B., Matsumoto, K., Yamamoto, M., and Watanabe, H. 1997. NMDA but not AMPA receptor antagonists impair the delay-interposed radial maze performance of rats. Pharmacol. Biochem. Behav. 58: 249-253.

Lisman, J. 2003. Long-term potentiation: Outstanding questions and attempted synthesis. Philos. Trans. R. Soc. Lond. B. Biol. Sci. 358: 829-842.

Logue, S.F., Paylor, R., and Wehner, J.M. 1997. Hippocampal lesions cause learning deficits in inbred mice in the Morris water maze and conditioned-fear task. Behav. Neurosci. 111: 104-113.

Lu, Y. and Wehner, J.M. 1997. Enhancement of contextual fear-conditioning by putative $(+/-)$ - $\alpha$-amino-3-hydroxy-5methylisoxazole-4-propionic acid (AMPA) receptor modulators and $\mathrm{N}$-methyl-D-aspartate (NMDA) receptor antagonists in DBA/2J mice. Brain Res. 768: 197-207.

Lubow, R.E. 1989. Latent inhibition and conditional attention theory. Cambridge University Press, Cambridge, UK.

Lubow, R.E., Kaplan, O., Abramovich, P., Rudnick, A., and Laor, N. 2000. Visual search in schizophrenia: Latent inhibition and novel pop-out effects. Schizophr. Res. 45: 145-156.

Marks, M.J., Romm, E., Campbell, S.M., and Collins, A.C. 1989 Variation of nicotinic binding sites among inbred strains. Pharmacol. Biochem. Behav. 33: 679-689.

Matsuyama, S., Matsumoto, A., Enomoto, T., and Nishizaki, T. 2000. Activation of nicotinic acetylcholine receptors induces long-term potentiation in vivo in the intact mouse dentate gyrus. Eur. J. Neurosci. 12: 3741-3747.

McGehee, D.S., Heath, M.J., Gelber, S., Devay, P., and Role, L.W. 1995. Nicotine enhancement of fast excitatory synaptic transmission in CNS by presynaptic receptors. Science 269: 1692-1696.

Mead, A.N. and Stephens, D.N. 1999. CNQX but not NBQX prevents expression of amphetamine-induced place preference conditioning: A role for the glycine site of the NMDA receptor, but not AMPA receptors. J. Pharmacol. Exp. Ther. 290: 9-15.

Mesches, M.H., Bianchin, M., and McGaugh, J.L. 1996. The effects of intra-amygdala infusion of the AMPA receptor antagonist CNQX on retention performance following aversive training. Neurobiol. Learn. Mem. 66: 324-340.

Misztal, M. and Danysz, W. 1995. Comparison of glutamate antagonists in continuous multiple-trial and single-trial dark avoidance. Behav. Pharmacol. 6: 550-561.

Nakayama, H., Numakawa, T., Ikeuchi, T., and Hatanaka, H. 2001. Nicotine-induced phosphorylation of extracellular signal-regulated protein kinase and CREB in PC12h cells. J. Neurochem. 79: 489-498.

Nomikos, G.G., Schilstrom, B., Hildebrand, B.E., Panagis, G., Grenhoff, J., and Svensson, T.H. 2000. Role of $\alpha 7$ nicotinic receptors in nicotine dependence and implications for psychiatric illness. Behav. Brain Res. 113: 97-103.

Nowak, L., Bregestovski, P., Ascher, P., Herbet, A., and Prochiantz, A. 1984. Magnesium gates glutamate-activated channels in mouse central neurones. Nature 307: 462-465.

Oswald, C.J., Yee, B.K., Rawlins, J.N., Bannerman, D.B., Good, M., and 
Honey, R.C. 2002. The influence of selective lesions to components of the hippocampal system on the orienting [correction of orientating] response, habituation and latent inhibition. Eur. J. Neurosci. 15: 1983-1990.

Parada, J., Czuczwar, S.J., and Turski, W.A. 1992. NBQX does not affect learning and memory tasks in mice. A comparison with d-CPPene and ifenprodil. Brain Res. Cog. Brain Res. 1: 67-71.

Parsons, C.G., Gruner, R., and Rozental, J. 1994. Comparative patch clamp studies on the kinetics and selectivity of glutamate receptor antagonism by 2,3-dihydroxy-6-nitro-7-sulfamoyl-benzo(F)quinoxaline (NBQX) and 1-(4-amino-phenyl)-4-methyl-7,8-methyl-endioxyl-5H-2,3benzodiazepine (GYKI 52466). Neuropharmacology 33: 589-604.

Paylor, R., Nguyen, M., Crawley, J.N., Patrick, J., Beaudet, A., and Orr-Urtreger, A. 1998. \& 7 nicotinic receptor subunits are not necessary for hippocampal-dependent learning or sensorimotor gating: A behavioral characterization of Acra7-deficient mice. Learn Mem. 5: 302-316.

Perry, D.C., Xiao, Y., Nguyen, H.N., Musachio, J.L., Davila-Garcia, M.I., and Kellar, K.J. 2002. Measuring nicotinic receptors with characteristics of $\alpha 4 \beta 2, \alpha 3 \beta 2$ and $\alpha 3 \beta 4$ subtypes in rat tissues by autoradiography. J. Neurochem. 82: 468-481.

Phillips, R.G. and LeDoux, J.E. 1992. Differential contribution of amygdala and hippocampus to cued and contextual fear conditioning. Behav. Neurosci. 106: 274-285.

. 1994. Lesions of the dorsal hippocampal formation interfere with background but not foreground contextual fear conditioning. Learn Mem. 1: 34-44.

Pitsikas, N., Rigamonti, A.E., Cella, S.G., and Muller, E.E. 2002. The non-NMDA receptor antagonist NBQX does not affect rats performance in the object recognition task. Pharmacol. Res. 45: $43-46$.

Porter, J.T., Cauli, B., Tsuzuki, K., Lambolez, B., Rossier, J., and Audinat, E. 1999. Selective excitation of subtypes of neocortical interneurons by nicotinic receptors. J. Neurosci. 19: 5228-5235.

Pouzet, B., Zhang, W.N., Weiner, I., Feldon, J., and Yee, B.K. 2004. Latent inhibition is spared by $N$-methyl-D-aspartate (NMDA)-induced ventral hippocampal lesions, but is attenuated following local activation of the ventral hippocampus by intracerebral NMDA infusion. Neuroscience 124: 183-194.

Quillfeldt, J.A., Schmitz, P.K., Walz, R., Bianchin, M., Zanatta, M.S., Medina, J.H., and Izquierdo, I. 1994. CNQX infused into entorhinal cortex blocks memory expression, and AMPA reverses the effect. Pharmacol. Biochem. Behav. 48: 437-440.

Rammes, G., Swandulla, D., Spielmanns, P., and Parsons, C.G. 1998. Interactions of GYKI 52466 and NBQX with cyclothiazide at AMPA receptors: Experiments with outside-out patches and EPSCs in hippocampal neurones. Neuropharmacology 37: 1299-1320.

Rickard, N.S., Poot, A.C., Gibbs, M.E., and Ng, K.T. 1994. Both non-NMDA and NMDA glutamate receptors are necessary for memory consolidation in the day-old chick. Behav. Neural. Biol. 62: $32-40$.

Riedel, G., Platt, B., and Micheau, J. 2003. Glutamate receptor function in learning and memory. Behav. Brain Res. 140: 1-47.

Rochford, J., Sen, A.P., and Quirion, R. 1996. Effect of nicotine and nicotinic receptor agonists on latent inhibition in the rat. J. Pharmacol. Exper. Therapeut. 277: 1267-1275.

Roerig, B., Nelson, D.A., and Katz, L.C. 1997. Fast synaptic signaling by nicotinic acetylcholine and serotonin 5-HT3 receptors in developing visual cortex. J. Neurosci. 17: 8353-8362.

Rogan, M.T., Staubli, U.V., and LeDoux, J.E. 1997. AMPA receptor facilitation accelerates fear learning without altering the level of conditioned fear acquired. J. Neurosci. 17: 5928-5935.

Role, L.W. and Berg, D.K. 1996. Nicotinic receptors in the development and modulation of CNS synapses. Neuron 16: 1077-1085.

Rudy, J.W. 1993. Contextual conditioning and auditory cue conditioning dissociate during development. Behav. Neurosci. 107: 887-891.

Sang, C.N., Hostetter, M.P., Gracely, R.H., Chappell, A.S., Schoepp, D.D., Lee, G., Whitcup, S., Caruso, R., and Max, M.B. 1998. AMPA/kainate antagonist LY293558 reduces capsaicin-evoked hyperalgesia but not pain in normal skin in humans. Anesthesiology 89: 1060-1067.

Sato, K., Morimoto, K., Yamada, N., Kuroda, S., and Hayabara, T. 1995. NBQX, a selective antagonist of the AMPA receptor, affects neither field potentials nor long-term potentiation in vivo. Brain Res. 683: $279-282$.
Schmajuk, N.A., Lam, Y.W., and Christiansen, B.A. 1994. Latent inhibition of the rat eyeblink response: Effect of hippocampal aspiration lesions. Physiol. Behav. 55: 597-601.

Schmajuk, N.A., Christiansen, B., and Cox, L. 2000. Haloperidol reinstates latent inhibition impaired by hippocampal lesions: Data and theory. Behav. Neurosci. 114: 659-670.

Sershen, H., Balla, A., Lajtha, A., and Vizi, E.S. 1997. Characterization of nicotinic receptors involved in the release of noradrenaline from the hippocampus. Neuroscience 77: 121-130.

Sheardown, M.J., Nielsen, E.O., Hansen, A.J., Jacobsen, P., and Honore, T. 1990. 2,3-Dihydroxy-6-nitro-7-sulfamoyl-benzo(F)quinoxaline: A neuroprotectant for cerebral ischemia. Science 247: 571-574.

Sheng, M. and Kim, M.J. 2002. Postsynaptic signaling and plasticity mechanisms. Science 298:776-780.

Sorenson, E.M., Shiroyama, T., and Kitai, S.T. 1998. Postsynaptic nicotinic receptors on dopaminergic neurons in the substantia nigra pars compacta of the rat. Neuroscience 87: 659-673.

Stephens, D.N. and Cole, B.J. 1996. AMPA antagonists differ from NMDA antagonists in their effects on operant DRL and delayed matching to position tasks. Psychopharmacology 126: 249-259.

Stiedl, O., Birkenfeld, K., Palve, M., and Spiess, J. 2000. Impairment of conditioned contextual fear of C57BL/6J mice by intracerebral injections of the NMDA receptor antagonist APV. Behav. Brain Res. 116: $157-168$.

Svendsen, F., Tjolsen, A., Rygh, L.J., and Hole, K. 1999. Expression of long-term potentiation in single wide dynamic range neurons in the rat is sensitive to blockade of glutamate receptors. Neurosci. Lett. 259: 25-28.

Swedberg, M.D., Jacobsen, P., and Honore, T. 1995. Anticonvulsant, anxiolytic and discriminative effects of the AMPA antagonist 2,3-dihydroxy-6-nitro-7-sulfamoyl-benzo(f)quinoxaline (NBQX). J. Pharmacol. Exp. Ther. 274: 1113-1121.

Tinsley, M.R., Quinn, J.J., and Fanselow, M.S. 2004. The role of muscarinic and nicotinic cholinergic neurotransmission in aversive conditioning: Comparing pavlovian fear conditioning and inhibitory avoidance. Learn. Mem. 11: 35-42.

Utsugisawa, K., Nagane, Y., Obara, D., and Tohgi, H. 2002. Over-expression of $\alpha 7$ nicotinic acetylcholine receptor induces sustained ERK phosphorylation and N-cadherin expression in PC12 cells. Brain Res. Mol. Brain Res. 106: 88-93.

Vaitl, D., Lipp, O., Bauer, U., Schuler, G., Stark, R., Zimmermann, M., and Kirsch, P. 2002. Latent inhibition and schizophrenia: Pavlovian conditioning of autonomic responses. Schizophr. Res. 55: 147-158.

Vianna, M.R., Alonso, M., Viola, H., Quevedo, J., de Paris, F., Furman, M., de Stein, M.L., Medina, J.H., and Izquierdo, I. 2000. Role of hippocampal signaling pathways in long-term memory formation of a nonassociative learning task in the rat. Learn. Mem. 7: 333-340.

Walker, D.L. and Davis, M. 1997. Double dissociation between the involvement of the bed nucleus of the stria terminalis and the central nucleus of the amygdala in startle increases produced by conditioned versus unconditioned fear. J. Neurosci. 17: 9375-9383.

Weiner, I. 2003. The "two-headed" latent inhibition model of schizophrenia: Modeling positive and negative symptoms and their treatment. Psychopharmacology 169: 257-297.

Willmore, C.B., Bespalov, A.Y., and Beardsley, P.M. 2002. Site-selective $N$-methyl-D-aspartate and

alpha-amino-3-hydroxy-5-methyl-4-isoxazolepropionate antagonists produce distinct effects in rats performing complex discriminations. Neurobiol. Learn. Mem. 78: 347-364.

Wonnacott, S. 1997. Presynaptic nicotinic ACh receptors. Trends Neurosci. 20: 92-98.

Yamazaki, Y., Hamaue, N., and Sumikawa, K. 2002. Nicotine compensates for the loss of cholinergic function to enhance long-term potentiation induction. Brain Res. 946: 148-152.

Yasoshima, Y., Morimoto, T., and Yamamoto, T. 2000. Different disruptive effects on the acquisition and expression of conditioned taste aversion by blockades of amygdalar ionotropic and metabotropic glutamatergic receptor subtypes in rats. Brain Res. 869: $15-24$.

Zhang, Z.W., Coggan, J.S., and Berg, D.K. 1996. Synaptic currents generated by neuronal acetylcholine receptors sensitive to a-bungarotoxin. Neuron 17: 1231-1240.

Received November 12, 2004; accepted in revised form May 23, 2005. 


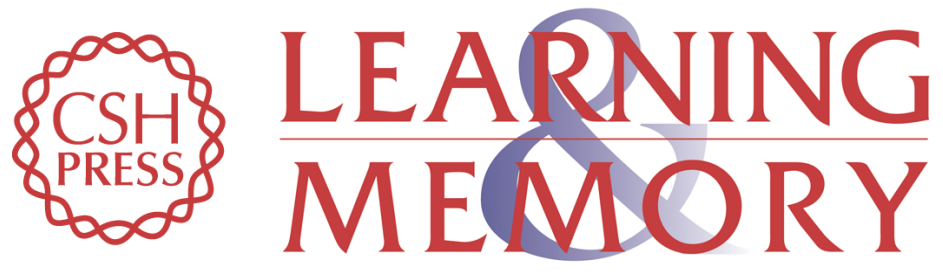

\section{Coantagonism of glutamate receptors and nicotinic acetylcholinergic receptors disrupts fear conditioning and latent inhibition of fear conditioning}

Thomas J. Gould and Michael C. Lewis

Learn. Mem. 2005, 12:

Access the most recent version at doi:10.1101//m.89105

References This article cites 121 articles, 23 of which can be accessed free at:

http://learnmem.cshlp.org/content/12/4/389.full.htmI\#ref-list-1

License

Email Alerting Receive free email alerts when new articles cite this article - sign up in the box at the Service top right corner of the article or click here. 